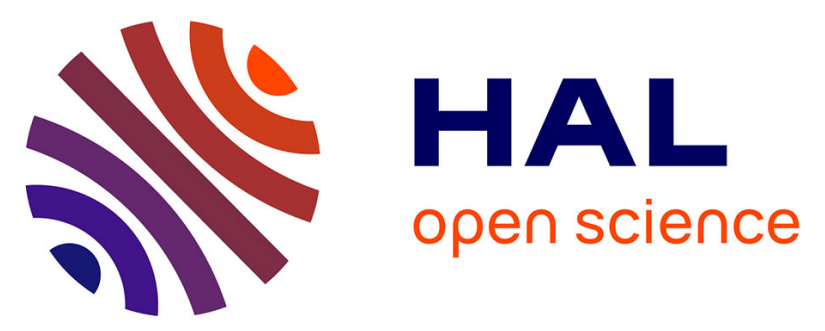

\title{
Efficacy and safety of steroid-sparing treatments in giant cell arteritis according to the glucocorticoids tapering regimen: A systematic review and meta-analysis
}

Anne-Laure Gérard, Noémie Simon-Tillaux, Youri Yordanov, Patrice Cacoub, Florence Tubach, David Saadoun, Agnès Dechartres

\section{To cite this version:}

Anne-Laure Gérard, Noémie Simon-Tillaux, Youri Yordanov, Patrice Cacoub, Florence Tubach, et al.. Efficacy and safety of steroid-sparing treatments in giant cell arteritis according to the glucocorticoids tapering regimen: A systematic review and meta-analysis. European Journal of Internal Medicine, 2021, 10.1016/j.ejim.2021.03.040 . hal-03207911

\section{HAL Id: hal-03207911 \\ https: / hal.sorbonne-universite.fr/hal-03207911}

Submitted on 26 Apr 2021

HAL is a multi-disciplinary open access archive for the deposit and dissemination of scientific research documents, whether they are published or not. The documents may come from teaching and research institutions in France or abroad, or from public or private research centers.
L'archive ouverte pluridisciplinaire HAL, est destinée au dépôt et à la diffusion de documents scientifiques de niveau recherche, publiés ou non, émanant des établissements d'enseignement et de recherche français ou étrangers, des laboratoires publics ou privés. 
Efficacy and safety of steroid-sparing treatments in giant cell arteritis according to the glucocorticoids tapering regimen: a systematic review and meta-analysis

Anne-Laure GÉRARD ${ }^{1}$, Noémie SIMON-TILLAUX ${ }^{1}$, Youri YORDANOV ${ }^{2}$, Patrice CACOUB $^{3}$, Florence TUBACH ${ }^{1}$, David SAADOUN ${ }^{3}$, Agnès DECHARTRES ${ }^{1}$

1. Sorbonne Université, INSERM, Institut Pierre Louis d'Epidémiologie et de Santé Publique, UMR-S 1136, AP-HP, Hôpital Pitié-Salpêtrière, Département de Santé Publique, Paris, France

2. Sorbonne Université, INSERM, Institut Pierre Louis d'Epidémiologie et de Santé Publique, UMR-S 1136, AP-HP, Hôpital Saint-Antoine, Service d'Accueil des Urgences, Paris, France

3. Sorbonne Université, INSERM U959, Immunopathology, Immunotherapies of autoimmunes and inflammatory diseases, RHU I2B, Labex Transimunom, AP-HP, Hôpital Pitié-Salpêtrière, Département de Médecine Interne et Immunologie Clinique, Paris, France, Centre national de référence Maladies Autoimmunes systémiques rares, Centre national de référence Maladies Auto-inflammatoires et Amylose.

\section{Correspondance to:}

Pr David Saadoun

Sorbonne Université, INSERM U959, Immunopathology, Immunotherapies of autoimmunes and inflammatory diseases, RHU I2B, Labex Transimunom

Hôpital Pitié-Salpêtrière, Département de Médecine Interne et Immunologie Clinique, 47-83 Boulevard de l’Hôpital 75013 Paris, France

Email: david.saadoun@aphp.fr

Phone: (33) 142178042 
Running title: Steroid-sparing treatments in giant cell arteritis

Word count: 3521

Ethics approval: Not applicable. This is a systematic review and meta-analysis on aggregated data. 
Objectives: To assess the efficacy and safety of adjuvant therapies in newly diagnosed or relapsing giant cell arteritis (GCA) in terms of relapse rate at week 52 (primary outcome) and to assess the impact of GC tapering regimen on adjuvant effectiveness.

Methods: For this systematic review and meta-analysis, we searched PubMed, EMBASE, CENTRAL, trial registries, from inception to November 2020. We included all randomized controlled trials (RCTs) and controlled prospective studies evaluating adjuvant treatments in GCA, without date or language restriction. Two reviewers independently selected studies, extracted data and assessed risk of bias. Quality of evidence was summarised with GRADE.

Results: Of the 680 records identified, 16 studies were included (1,068 participants) evaluating various adjuvant therapies compared to GC only. No study compared adjuvants with each other. Risk of bias was high in 5/7 trials evaluating our primary outcome. Risk of relapse at week 52 was reduced for only the anti-IL6 and IL6-receptor drug class versus the control $(\mathrm{RR}=0.45,95 \% \mathrm{CI} 0.30-0.66, \mathrm{I} 2=38 \%)$, particularly tocilizumab $(\mathrm{RR}=0.38,95 \% \mathrm{CI}$ $0.23-0.63, \mathrm{I} 2=42 \%$ ) with a moderate quality of evidence. We found no significant interaction according to GC tapering regimen. Our meta-analysis did not show a significant benefit for methotrexate. Except for dapsone, ciclosporine and hydroxychloroquine, other adjuvants did not seem to show increased risk of adverse events.

Conclusions: Tocilizumab seems to reduce the relapse rate in GCA at week 52 but the quality of evidence was moderate. No other molecule has shown efficacy. No significant interaction on relapse rate by GC tapering regimen was found.

Study registration: PROSPERO CRD42020172011.

Key-words: Giant cell arteritis, steroid-sparing treatment, glucocorticoids, systematic review, meta-analysis 


\section{List of abbreviations used}

DMARD: disease-modifying antirheumatic drug

bDMARD: biologic disease-modifying antirheumatic drug

csDMARD: conventional synthetic disease-modifying antirheumatic drug

EULAR: European League Against Rheumatism

GC: glucocorticoid

GCA: giant cell arteritis

ICTRP: International Clinical Trials Registry Platform

IL: interleukin

IL6R: interleukin-6 receptor

IPD: individual patient data

ITT: intention to treat

ITTm: modified intention to treat

IV: intravenous

LOCF: last observation carried forward

NA: not available

PMR: polymyalgia rheumatica

$\mathrm{p}_{\text {het }}$ : $\mathrm{p}$-value heterogeneity

PO: by mouth

RCT: randomized controlled trial

$\mathrm{RR}$ : risk ratio

SMD: standardized mean difference

SC: subcutaneous

TNF: tumor necrosis factor

95\%CI: 95\% confidence interval 


\section{INTRODUCTION}

Giant cell arteritis (GCA) is the most common systemic vasculitis in Western countries, with an annual incidence of 10 to 20 per 100,000 adults older than 50 years and increasing with age[1]. Its prognosis can be severe, particularly because of ophthalmic involvement, with permanent visual loss occurring in up to $14 \%$ of patients[2], as well as risk of aortitis[3] or stroke[4]. Several clinical patterns of GCA have been described, with cranial and large-vessel GCA the most frequently encountered[5]. Glucocorticoids (GC) are the cornerstone of GCA medical treatment and should be started at high doses for 2 to 4 weeks and then slowly tapered to avoid relapse, with a withdrawal between 18 and 24 months[6]. Despite this slow tapering regimen, 50\% of GCA patients experience relapse[7], thus resulting in reintensification of treatment. Long-term use of GC is associated with important side effects including osteoporosis, diabetes, cardiovascular diseases and infections[1]. In general, GCA patients are older and often have comorbidities that could contraindicate high-dose and longterm steroid treatment[8].

Therefore, the effectiveness of adjuvant therapies allowing for GC sparing needs assessment. Methotrexate was the first adjuvant therapy evaluated and showed a modest effect on relapse rate and GC sparing[9]. Biologics were then studied, with several studies focusing on tumor necrosis factor (TNF) inhibitors[10-12]. Recently, tocilizumab, a monoclonal antibody directed against interleukin 6 receptor (IL6R), showed a beneficial effect on relapse rate and GC sparing in two randomized controlled trials (RCTs)[13,14]. For most adjuvant therapies, clinical trials had a small sample size and inconclusive results. In addition, different GC tapering regimens were used, which may have affected the relapse rate. 
The aim of this systematic review and meta-analysis was to assess the efficacy and safety of adjuvant therapies in GCA patients in terms of relapse rate and GC cumulative dose and to assess the impact of the GC tapering regimen on the effectiveness of adjuvants. 


\section{MATERIAL AND METHODS}

This systematic review is reported in accordance with the PRISMA statement[15]. The protocol was registered on PROSPERO (CRD42020172011).

\section{Data sources and search strategy}

The following electronic databases were searched on March 5, 2020 (update on November 10, 2020): MEDLINE via PubMed, EMBASE, Cochrane Library. A dedicated search algorithm was developed for each database (Appendix 1).

We conducted a manual search of key internal medicine and rheumatology journals for the last 10 years. We also searched the WHO International Clinical Trials Registry Platform (ICTRP) and ClinicalTrials.gov as well as the abstracts of the main congresses (American College of Rheumatology congress and European League Against Rheumatism (EULAR)) for the last 5 years. Finally, we screened all reference lists for further references.

\section{Eligibility criteria and selection process}

All reports of RCTs and controlled prospective studies evaluating any steroid-sparing agents in patients with newly diagnosed or recurrent GCA were included whatever the language, publication date or follow-up duration. We excluded retrospective studies, expert opinion, reviews and meta-analyses. Our primary outcome was relapse rate at week 52. Relapse was defined as the recurrence of clinical symptoms and/or increased values of biological inflammatory markers leading to an intensification of treatment. The main secondary outcomes were short-term relapse rate (week 26), medium- and long-term relapse rate (from weeks 52 to 104), medium- and long-term cumulative GC dose, severe relapse rate (visual impairment, stroke, aortic dissection or aneurism), time to relapse and relapse-free survival. 
Safety outcomes included the rate of adverse events, serious adverse events, death, infection and severe infection.

Retrieved records were managed with Zotero v5.0. Two review authors (A-LG and YY or NS-T) independently identified eligible studies by screening titles and abstracts and then full texts. All disagreements were resolved by discussion with the help of a third reviewer (AD) to reach consensus.

\section{Data extraction}

Two review authors (A-LG and NS-T) independently extracted data from the included studies by using a standardized data extraction form. Disagreements were resolved by discussion with the help of a third reviewer (AD) to reach consensus. We sought additional information from the study authors if necessary.

\section{Data items}

We collected the following items:

- General characteristics: first author name, year and journal of publication, recruitment period, country, language, study design, funding sources.

- Population characteristics: age, sex, main eligibility criteria, newly diagnosed disease or relapse, cranial or large-vessel GCA, rate of visual impairment.

- Experimental intervention: which adjuvant therapy, dose, duration, mode of administration.

- Control group: no treatment, placebo or another therapy.

- GC treatment: tapering regimen as well as GC initial dose and total duration. We initially defined rapid GC tapering regimen as a GC tapering therapy lasting $\leq 6$ months or 26 weeks[16]. We slightly modified this definition after data extraction to 
have a more homogeneous definition across studies and considered GC tapering therapy $\leq 28$ weeks as rapid.

- Sample size and whether it was consistent with planned sample size, as well as the hypotheses used for calculation.

- Results: for each arm, we collected the number of randomized and analyzed participants, the number of events for binary outcomes and the cumulative GC dose. When relapse was not reported, we considered that the number of participants with relapse was equal to the number of participants minus the number of participants in remission. When necessary, we used the Revman Calculator tool and Wan's Excel spreadsheet[17] to estimate the mean and standard deviation from the median and range or interquartile range (IQR)[18].

\section{Evaluation of risk of bias in individual studies}

The risk of bias was independently assessed by 2 review authors (A-LG and NS-T) with the updated version of the Cochrane Risk of Bias tool[19]. Disagreements were resolved by discussion with the help of a third reviewer (AD) to reach consensus. The risk of bias was assessed focusing first on our primary outcome and then on the cumulative GC dose.

\section{Data synthesis}

\section{Evaluation of the efficacy and safety of adjuvant therapies}

Meta-analyses involved only RCTs to synthesize efficacy and safety. We considered each drug separately and then by mechanism of action.

According to the Cochrane handbook[18], when trials included more than 2 intervention groups, we determined which one was relevant for the meta-analysis. If 2 or more groups were relevant, we created separate comparisons of an experimental group to a control group, 
without using the same participants more than once. We tried to compare groups with the same GC tapering regimen or, if not possible, to minimize the differences in GC duration.

We used both fixed- and random-effects models and compared their results. We performed a sensitivity analysis by using the Knapp-Hartung model[20]. The measure of association was the risk ratio $(\mathrm{RR})$ for binary data and mean difference for quantitative data. Statistical analysis was according to intention-to-treat.

We evaluated statistical heterogeneity across trials by visually inspecting forest plots and by the Cochran $\mathrm{Q}$ test and $\mathrm{I}^{2}$ and $\mathrm{Tau}^{2}$ statistics. An $\mathrm{I}^{2}$ value $>50 \%$ or $\mathrm{p}<0.1$ was considered substantial heterogeneity[18].

We planned a priori subgroup analyses according to risk of bias and clinical pattern (i.e., cranial vs large-vessel GCA) as well as a sensitivity analysis including only studies published from 2000 onward. We evaluated the risk of reporting bias by using funnel plots.

\section{Evaluation of the impact of the GC tapering regimen on adjuvant effectiveness}

To explore the impact of GC tapering regimen on adjuvant effectiveness, we conducted a subgroup analysis according to the GC tapering regimen: rapid, slow, or rapid in the experimental group and slow in the control group, following the definition reported above. Interaction was evaluated in a random-effects meta-regression model. We considered separately trials evaluating tocilizumab and other treatments because of no evidence of efficacy for these other treatments as compared with tocilizumab.

\section{Grading of the quality of evidence}

The quality of evidence for each therapeutic class or molecule was graded high, moderate, low, or very low[21] for key outcomes by using the Grading of Recommendations Assessment, Development and Evaluation working group (GRADE) tool[22]. Key outcomes 
were relapse rate at week 52, medium- and long-term relapse rate, medium- and long-term severe relapse rate, medium- and long-term cumulative GC dose, adverse events and infection rate.

All analyzes were performed with Review Manager 5.3[23] and R v3.6[24]. The grading of the evidence involved using Gradepro[25]. 


\section{RESULTS}

\section{Study selection and characteristics}

The electronic search identified 679 records, and we identified one additional record from the ICTRP. We finally included 16 studies, with 13 studies for the quantitative meta-analyses (Figure 1).

Among the 16 included studies, 2 were not published[26,27]. All but one[28] were RCTs, with 2 or more parallel groups (SM Table 1). A total of 1,068 participants were included in the 16 studies. The median sample size was 46 participants (IQR 24-75.7; range 13-251). Women accounted for $78 \%$ of patients. All participants were $\geq 50$ years old. Eight studies concerned biologic DMARDs (bDMARDs): anti-IL6 and anti-IL6R drugs ( $\mathrm{n}=3)$, TNF- $\alpha$ inhibitors ( $n=3)$, CTLA4-Ig $(n=1)$ and anti-IL1 drug $(n=1)$. Five studies concerned conventional synthetic DMARDs (csDMARDs): methotrexate $(n=3)$, leflunomide $(n=1)$ and hydroxychloroquine $(n=1)$. Treatment duration ranged from 12 to 96 weeks. The control group was a placebo in 12 studies $(75 \%)$ and no treatment in $4(25 \%)$. No study directly compared 2 adjuvant therapies. Relapse definitions were similar between studies and comparable with our definition. Of the 15 RCTs, 5 were prematurely stopped because of low recruitment rate[10,12], no therapeutic benefit after a planned interim analysis[11], for administrative reasons[29] or for strategic reasons unrelated to any safety issue[26]. A sample size calculation was reported in 11 trials (73\%): the targeted sample size was not reached in 6 (55\%). Hypotheses for sample size calculation were available for 9 trials (SM Table 2). When comparing results to hypotheses, the expected between-group difference was reached in only 1 trial[14].

\section{Risk of bias within trials}


The overall risk of bias for relapse rate at week 52 was assessed as high for 5 of the 7 trials evaluating this outcome and as some concerns for 2 [10,14] (SM Figure 1). Missing outcome data suggested high risk of bias for 4 studies. For relapse at week 52, the median proportion of missing data across trials was $23 \%$ (IQR 16-62). Handling of missing outcome data was not reported in $9(56 \%)$ trials or was not done with a recommended method in $3(19 \%)$. The overall risk of bias rating for the medium- and long-term cumulative GC dose was high for 7 studies[12-14,16,27,29,30] and some concerns for 1 study[31] (SM Figure 2).

\section{Synthesis of results}

We excluded the observational study[28] from the quantitative meta-analyses and 2 ciclosporine trials[32,33] because they did not report any data for our outcomes. Only very few studies reported time to relapse or relapse-free survival, therefore, no meta-analysis was performed for these outcomes. All results were consistent by using a fixed- or random-effects model.

\section{Relapse rate at week 52}

Risk of relapse was significantly lower for participants who received anti-IL6 or -IL6R drugs versus placebo ( 3 trials, 5 comparisons, $\mathrm{RR}=0.45$, 95\%CI 0.30 to 0.66 ); heterogeneity was moderate ( $\mathrm{p}_{\text {het }}=0.17, \mathrm{I}^{2}=38 \%, \mathrm{Tau}^{2}=0.07$ ) (Figure 2 ). Tocilizumab (anti-IL6R) significantly reduced the relapse risk ( 2 trials, 3 comparisons, $\mathrm{RR}=0.38,95 \% \mathrm{CI} 0.23$ to 0.63 ), with moderate heterogeneity ( $\mathrm{p}_{\text {het }}=0.18, \mathrm{I}^{2}=42 \%$, Tau ${ }^{2}=0.08$ ). In contrast, sirukumab (anti-IL6) did not significantly decrease the risk of relapse ( 1 trial, 2 comparisons, $\mathrm{RR}=0.61,95 \% \mathrm{CI} 0.36$ to 1.05). TNF- $\alpha$ inhibitors, methotrexate and abatacept did not significantly reduce risk of relapse. Results were similar using a Knapp-Hartung model for anti-IL6 and -IL6R (RR=0.45, 
95\% CI 0.25 to 0.79$)$ and TNF- $\alpha$ inhibitors ( $\mathrm{RR}=0.78,95 \% \mathrm{CI} 0.26$ to 2.40$)$ but was no longer significant for tocilizumab ( $\mathrm{RR}=0.38,95 \% \mathrm{CI} 0.11$ to 1.26$)$.

Funnel plot examination did not reveal evidence of asymmetry (SM Figure 3).

\section{Medium- and long-term relapse rate}

We found similar results for medium- and long-term relapse (SM Figure 4). In addition, the observational study evaluating leflunomide showed a potential benefit on relapse as compared with the GC-only group ( $\mathrm{RR}=0.34,95 \% \mathrm{CI} 0.13$ to 0.91$)$.

\section{Medium- and long-term cumulative GC dose}

Anti-IL6 and -IL6R showed a significant reduction in GC cumulative dose (3 trials, 5 comparisons, $\mathrm{SMD}=-0.91,95 \% \mathrm{CI}-1.46$ to -0.36 ), but heterogeneity was substantial ( $\mathrm{p}_{\text {het }}=0.005, \mathrm{I}^{2}=73 \%, \mathrm{Tau}^{2}=0.26$ ) (Figure 3). Etanercept was the only TNF- $\alpha$ inhibitor for which medium- and long-term GC cumulative dose data were available, showing a significant reduction versus placebo ( $\mathrm{SMD}=-1.10,95 \% \mathrm{CI}-2.14$ to -0.06$)$. We found no significant difference for methotrexate and hydroxychloroquine. The observational study of leflunomide showed a potential slight benefit as compared with the GC-only group (SMD -.57, 95\%CI 1.07 to -0.07$)$.

\section{Short-term relapse rate (week 26)}

Only 5 studies had available data to analyze short-term relapse rate. Apart from tocilizumab, no other drugs had any benefit on relapse at week 26 as compared with placebo (SM Figure $5)$. 


\section{Severe relapses}

Data on severe relapses were available from 4 studies (SM Figure 6). The studies were heterogeneous and could not be pooled in a meta-analysis. All severe relapses but 2 were visual impairments.

\section{Safety}

We found no evidence of difference in frequency of adverse events or serious adverse events among anti-IL6 and -IL6R, TNF- $\alpha$ inhibitors and CTLA4-Ig and anti-IL1 drugs versus the control group (SM Figure 7a and 7b). Risk of adverse events was increased but not significantly with hydroxychloroquine. Risk of infection was significantly increased with TNF- $\alpha$ inhibitors as compared with placebo (3 trials, RR=1.46, 95\%CI 1.03 to 2.08 , $\mathrm{p}_{\text {het }}=0.48, \mathrm{I}^{2}=0 \%, \mathrm{Tau}^{2}=0$ ), but the risk of severe infection did not differ (SM Figure $7 \mathrm{c}$ and 7d). Adverse events in trials assessing methotrexate were reported by events and were not comparable with those with other drugs. However, safety data did not seem to differ between the 2 groups. Ciclosporine and dapsone were poorly tolerated. No pneumocystosis was reported in the trials.

A few deaths were reported. Villiger et al. reported 1 death in the placebo group[13]. Seror $e t$ al. reported 3 deaths[10], 1 in the adalimumab group and 2 in the placebo group. Hoffman et al. reported 3 deaths, 2 in the methotrexate group and 1 in the placebo group[16]. Liozon et al. reported 3 deaths overall with no further detail[34].

\section{Subgroup and sensitivity analyses}


Subgroup analysis by risk of bias and clinical patterns was not possible because of the small number of studies. The sensitivity analysis including only trials published after 2000 found consistent results.

\section{Evaluation of the impact of the GC tapering regimen on adjuvant effectiveness}

When specified, most trials had a rapid GC tapering regimen (Appendix Table A1). We found no significant interaction on relapse rate by $\mathrm{GC}$ tapering regimen $(\mathrm{p}=0.33$ and $\mathrm{p}=0.20$ for rapid GC tapering regimen in both groups and rapid GC tapering regimen in the experimental group vs slow in the control group, respectively). We did not have enough trials to analyze the impact of the GC tapering regimen on relapse rate by therapeutic class. Tocilizumab was the only drug evaluated in more than 1 trial with different GC tapering regimens[13,14]. Risk of relapse was significantly reduced with tocilizumab regardless of GC tapering regimen. When excluding tocilizumab trials, our results suggested that a rapid GC tapering regimen tended to favor the experimental treatment, but the interaction test was not statistically significant (Figure 4).

\section{Quality of evidence}

Certainty of the evidence was moderate for relapse rate at week 52 and in the medium and long term; rate of adverse events and infections for tocilizumab and anti-IL6 and -IL6R; and infection rate for TNF- $\alpha$ inhibitors. Certainty of the evidence for other outcomes and treatments was graded very low to low (SM Table 3). 


\section{DISCUSSION}

In this meta-analysis, only anti-IL6 and IL6R agents, driven by tocilizumab, reduced the relapse rate in GCA. No other drug has shown efficacy. Apart from ciclosporine, dapsone and hydroxychloroquine, the risk of adverse events was not increased except a higher risk of infection for TNF- $\alpha$ inhibitors. Although our results suggest that adopting a rapid or low GC tapering regimen may influence the treatment effect, we were unable to find a significant interaction because of the lack of trials and heterogeneity. Our results also revealed important limitations of included studies, such as high risk of bias and small sample size. When hypotheses for sample size calculation were reported, the expected between-group difference was generally not achieved. This situation contributed to the lack of power and decreased the quality of evidence.

Because of the associated iatrogenic effects, it is crucial to demonstrate the validity of steroidsparing treatments[1], particularly in patients with GCA who are often elderly and comorbid[8].

Tocilizumab seems to be effective for GC sparing in GCA. This result is consistent with both rapid and slow GC tapering regimens. The safety profile seems acceptable, at least for shortterm use. The US Food and Drug Administration[35] and European Medicines Agency[36] have approved tocilizumab for GC sparing in GCA. However, the optimal duration of treatment is still unknown, and the risk of relapse after discontinuation is high[37-39]. In addition, the benefit in severe GCA, such as ophthalmic involvement or stroke, has not been shown but a trial is ongoing[40].

In some guidelines, methotrexate is recommended as first-line adjuvant therapy[6,41]. However, our meta-analysis did not show a significant benefit for methotrexate, which 
contrasts with the positive effect on relapses and GC cumulative dose found in a previous individual patient data (IPD) meta-analysis[9]. This IPD meta-analysis analyzed time-to-event outcomes with Cox proportional-hazard models, which may partly explain the difference with our results. In addition, heterogeneity was not accounted for in this study. We repeated the meta-analysis from the hazard ratios reported in the forest plot and found no significant difference by using a random-effects model.

We found no beneficial effect of abatacept on relapse rate, whereas a previous study showed a significant difference for relapse-free survival rate within 12 months[42]. However, the pvalue was 0.049 using a one-sided test, whereas two-sided tests are more adapted.

One of our objectives was to evaluate whether there was a difference in adjuvant effectiveness by GC tapering regimen. EULAR recommends tapering the GC dose to $<5 \mathrm{mg}$ /day after 1 year, stopping GC after 2 years of treatment[6], but this recommendation was not followed for the control group in 5 of the 11 trials reporting this information in our review. Such rapid regimen may seem unfavorable for patients in the control group, increasing the risk of relapse, which might lead to a possible overestimation of treatment effect. Unfortunately, we did not have enough trials to fully explore this situation, and the interaction test was not significant. Tocilizumab seems to have an effect on relapse rate whatever the GC tapering regimen, but the number of trials was limited. In contrast, when considering other treatments, our results suggest that a rapid GC tapering regimen tends to favor the experimental treatment. Mainbourg et al. previously showed that the duration of scheduled GC therapy in GCA was negatively associated with relapse rate in 17 studies (decreased rate of $1.7 \%$ for one additional month)[7]. Similarly, a meta-analysis in anti-neutrophil cytoplasm antibody vasculitis showed longer courses of GC associated with fewer relapses[43].

The quality of evidence was limited by several methodological weaknesses in individual trials. Most studies had a high risk of bias and a limited sample size. Some studies were 
prematurely stopped, mostly because of a low recruitment rate. In fact, tight inclusion criteria including typical findings of GCA on temporal biopsy were often mandatory in the oldest trials[10,12,27,31,32,34]. The diagnosis of GCA is currently based on a set of evidence, including physical or laboratory features and compatible imaging examinations[44], without the need for a positive temporal artery biopsy, which can be falsely negative[45]. Ultrasonography, magnetic resonance imaging and fluorodeoxyglucose F18 positron emission tomography are increasingly being used in clinical practice and are becoming more effective for the diagnosis of GCA[46-49]. These imaging techniques would allow more patients to be included in trials.

Included studies did not report the same outcomes and only 7 of 16 studies included reported our primary outcome. The Outcome Measures in Rheumatology (OMERACT) vasculitis working group Large-Vessel Vasculitis Task Force is developing a core set of outcome measures for large-vessel vasculitis for use in clinical trials[50]. Future clinical trials of GCA should take into account the limitations discussed in this review, in particular the need for standardizing outcomes and the GC tapering regimen to facilitate comparison across studies and drugs. Several clinical trials are ongoing including a trial comparing 2 adjuvant treatments (tocilizumab versus methotrexate) (SM Table 4).

Our study has limitations. First, there was a lack of studies. Except for tocilizumab, methotrexate and ciclosporine, other drugs were evaluated in only one study. Studies were heterogeneous in terms of drugs belonging to different therapeutic classes; populations with newly diagnosed, relapsing or controlled GCA; and various timing of randomization and lengths of follow-up. We defined a GC tapering therapy $\leq 28$ weeks as a rapid tapering regimen[16]. However, this definition is debatable. Finally, our meta-analysis was based on aggregated data and could be affected by the poor quality of reporting in original articles. 
In conclusion, tocilizumab was the only drug showing a significantly lower incidence of relapse with GCA at week 52 as compared with the control group but with a moderate quality of evidence. We did not find a significant interaction by GC tapering regimen, possibly because of the low number of studies involved. It is important to standardize outcomes and glucocorticoids tapering regimen in future trials to facilitate comparisons and meta-analyses. 
We thank the authors for their responses to our requests: Prof Seror, Prof Aouba, Prof Sailler and Ms Velasco Avisbal.

We also thank Laura Smales, BioMedEditing for English corrections.

Anne-Laure Gerard was funded by INSERM.

\section{STUDY INFORMATION}

Funding source: This research did not receive any specific grant from funding agencies in the public, commercial or not-for-profit sectors.

Competing interests: None.

Data sharing: All data will be available upon request for academic researchers.

\section{AUTHOR CONTRIBUTION}

Anne-Laure Gérard: study conception, investigation, search, study selection and data extraction, statistical analysis, manuscript writing Noemie-Simon Tillaux: investigation, study selection and data extraction, manuscript review and editing

Youri Yordanov: investigation, study selection and data extraction, manuscript review and editing

Patrice Cacoub: manuscript review and editing 
Florence Tubach: Ressource acquisition, study conception, manuscript review and editing David Saadoun: study conception, investigation, supervision, manuscript review and editing Agnes Dechartres: study conception, investigation, supervision, manuscript writing 


\section{REFERENCES}

[1] Mahr A, Belhassen M, Paccalin M, Devauchelle-Pensec V, Nolin M, Gandon S, et al. Characteristics and management of giant cell arteritis in France: a study based on national health insurance claims data. Rheumatol Oxf Engl 2020;59:120-8. https://doi.org/10.1093/rheumatology/kez251.

[2] González-Gay MA, Blanco R, Rodríguez-Valverde V, Martínez-Taboada VM, DelgadoRodriguez M, Figueroa M, et al. Permanent visual loss and cerebrovascular accidents in giant cell arteritis: predictors and response to treatment. Arthritis Rheum 1998;41:1497504.

[3] Vautier M, Dupont A, de Boysson H, Comarmond C, Mirault T, Mekinian A, et al. Prognosis of large vessel involvement in large vessel vasculitis. J Autoimmun 2020;108:102419. https://doi.org/10.1016/j.jaut.2020.102419.

[4] Pariente A, Guédon A, Alamowitch S, Thietart S, Carrat F, Delorme S, et al. Ischemic stroke in giant-cell arteritis: French retrospective study. J Autoimmun 2019;99:48-51. https://doi.org/10.1016/j.jaut.2019.01.009.

[5] Brack A, Martinez-Taboada V, Stanson A, Goronzy JJ, Weyand CM. Disease pattern in cranial and large-vessel giant cell arteritis. Arthritis Rheum 1999;42:311-7. https://doi.org/10.1002/1529-0131(199902)42:2<311::AID-ANR14>3.0.CO;2-F.

[6] Hellmich B, Agueda A, Monti S, Buttgereit F, de Boysson H, Brouwer E, et al. 2018 Update of the EULAR recommendations for the management of large vessel vasculitis. Ann Rheum Dis 2020;79:19-30. https://doi.org/10.1136/annrheumdis-2019-215672.

[7] Mainbourg S, Addario A, Samson M, Puéchal X, François M, Durupt S, et al. Prevalence of Giant Cell Arteritis Relapse in Patients Treated With Glucocorticoids: A Meta-Analysis. Arthritis Care Res 2020;72:838-49. https://doi.org/10.1002/acr.23901.

[8] Chazal T, Lhote R, Rey G, Haroche J, Eb M, Amoura Z, et al. Giant-cell arteritis-related mortality in France: A multiple-cause-of-death analysis. Autoimmun Rev 2018;17:121924. https://doi.org/10.1016/j.autrev.2018.06.012.

[9] Mahr AD, Jover JA, Spiera RF, Hernández-García C, Fernández-Gutiérrez B, Lavalley MP, et al. Adjunctive methotrexate for treatment of giant cell arteritis: an individual patient data meta-analysis. Arthritis Rheum 2007;56:2789-97. https://doi.org/10.1002/art.22754.

[10] Seror R, Baron G, Hachulla E, Debandt M, Larroche C, Puechal X, et al. Adalimumab for steroid sparing in patients with giant-cell arteritis: results of a multicentre randomised controlled trial. Ann Rheum Dis 2014;73:2074-81. https://doi.org/10.1136/annrheumdis-2013-203586.

[11] Hoffman G, Cid M, Rendt-Zagar K, Merkel P, Weyand C, Stone J, et al. Infliximab for maintenance of glucocorticosteroid-induced remission of giant cell arteritis: a randomized trial. Ann Intern Med 2007;146:621-630. https://doi.org/10.7326/00034819-146-9-200705010-00004.

[12] Martínez-Taboada V, Rodríguez-Valverde V, Carreño L, López-Longo J, Figueroa M, Belzunegui J, et al. A double-blind placebo controlled trial of etanercept in patients with giant cell arteritis and corticosteroid side effects. Ann Rheum Dis 2008;67:625-630. https://doi.org/10.1136/ard.2007.082115.

[13] Villiger PM, Adler S, Kuchen S, Wermelinger F, Dan D, Fiege V, et al. Tocilizumab for induction and maintenance of remission in giant cell arteritis: a phase 2, randomised, double-blind, placebo-controlled trial. Lancet Lond Engl 2016;387:1921-7. https://doi.org/10.1016/S0140-6736(16)00560-2. 
[14] Stone JH, Tuckwell K, Dimonaco S, Klearman M, Aringer M, Blockmans D, et al. Trial of Tocilizumab in Giant-Cell Arteritis. N Engl J Med 2017;377:317-28. https://doi.org/10.1056/NEJMoa1613849.

[15] Moher D, Liberati A, Tetzlaff J, Altman DG, The PRISMA Group. Preferred Reporting Items for Systematic Reviews and Meta-Analyses: The PRISMA Statement. PLoS Med 2009;6:e1000097. https://doi.org/10.1371/journal.pmed.1000097.

[16] Hoffman GS, Cid MC, Hellmann DB, Guillevin L, Stone JH, Schousboe J, et al. A multicenter, randomized, double-blind, placebo-controlled trial of adjuvant methotrexate treatment for giant cell arteritis. Arthritis Rheum 2002;46:1309-18. https://doi.org/10.1002/art.10262.

[17] Wan X, Wang W, Liu J, Tong T. Estimating the sample mean and standard deviation from the sample size, median, range and/or interquartile range. BMC Med Res Methodol 2014;14:135. https://doi.org/10.1186/1471-2288-14-135.

[18] Higgins JPT, Thomas J, Chandler J, Cumpston M, Li T, Page MJ, Welch VA (editors). Cochrane Handbook for Systematic Reviews of Interventions. 2nd Edition. Chichester (UK): John Wiley \& Sons, 2019. n.d.

[19] Sterne JAC, Savović J, Page MJ, Elbers RG, Blencowe NS, Boutron I, et al. RoB 2: a revised tool for assessing risk of bias in randomised trials. BMJ 2019;366:14898. https://doi.org/10.1136/bmj.14898.

[20] Cornell JE, Mulrow CD, Localio R, Stack CB, Meibohm AR, Guallar E, et al. RandomEffects Meta-analysis of Inconsistent Effects: A Time for Change. Ann Intern Med 2014;160:267-70. https://doi.org/10.7326/M13-2886.

[21] Schünemann H, Brożek J, Guyatt G, Oxman A, editor(s). Handbook for grading the quality of evidence and the strength of recommendations using the GRADE approach (updated October 2013). GRADE Working Group, 2013. Available from gdt.guidelinedevelopment.org/app/handbook/handbook.html. n.d.

[22] Guyatt GH, Oxman AD, Vist GE, Kunz R, Falck-Ytter Y, Alonso-Coello P, et al. GRADE: an emerging consensus on rating quality of evidence and strength of recommendations. BMJ 2008;336:924-6. https://doi.org/10.1136/bmj.39489.470347.AD.

[23] The Cochrane Collaboration. Review Manager (RevMan) [Computer program]. Version 5.3. Copenhagen: The Nordic Cochrane Centre 2014.

[24] Viechtbauer W (2010). "Conducting meta-analyses in R with the metafor package." Journal of Statistical Software, 36(3), 1-48. https://www.jstatsoft.org/v36/i03/ n.d.

[25] GRADEpro GDT: GRADEpro Guideline Development Tool [Software]. McMaster University, 2015 (developed by Evidence Prime, Inc.). Available from gradepro.org. n.d.

[26] A randomised, double-blind, placebo-controlled proof of concept study of the efficacy and the safety of gevokizumab in the treatment of patients with giant cell arteritis. 2016.

[27] NCT00430807. Hydroxychloroquine in Giant Cell Arteritis. Https://ClinicaltrialsGov/Show/NCT00430807 2007.

[28] Hocevar A, Jese R, Rotar Z, Tomsic M. Does leflunomide have a role in giant cell arteritis? An open-label study. Clin Rheumatol 2019;38:291-6. https://doi.org/10.1007/s10067-018-4232-x.

[29] Schmidt WA, Dasgupta B, Luqmani R, Unizony SH, Blockmans D, Lai Z, et al. A Multicentre, Randomised, Double-Blind, Placebo-Controlled, Parallel-Group Study to Evaluate the Efficacy and Safety of Sirukumab in the Treatment of Giant Cell Arteritis. Rheumatol Ther 2020. https://doi.org/10.1007/s40744-020-00227-2.

[30] Spiera R, Mitnick H, Kupersmith M, Richmond M, Spiera H, Peterson M, et al. A prospective, double-blind, randomized, placebo controlled trial of methotrexate in the treatment of giant cell arteritis (GCA). Clin Exp Rheumatol 2001;19:495-501. 
[31] Jover J, Hernández-García C, Morado I, Vargas E, Bañares A, Fernández-Gutiérrez B. Combined treatment of giant-cell arteritis with methotrexate and prednisone. a randomized, double-blind, placebo-controlled trial. Ann Intern Med 2001;134:106-114. https://doi.org/10.7326/0003-4819-134-2-200101160-00010.

[32] Schaufelberger C, Mollby H, Uddhammar A, Bratt J, Nordborg E. No additional steroidsparing effect of cyclosporine A in giant cell arteritis. Scand J Rheumatol 2006;35:3279. https://doi.org/10.1080/03009740500474537.

[33] Schaufelberger C, Andersson R, Nordborg E. No additive effect of cyclosporin A compared with glucocorticoid treatment alone in giant cell arteritis: results of an open, controlled, randomized study. Br J Rheumatol 1998;37:464-465. https://doi.org/10.1093/rheumatology/37.4.464.

[34] Liozon F, Barrier J, Vidal E, Venot J. Treatment of giant cell arteritis with dapsone: effectiveness and side-effects. Rev Med Interne 1990;11:364-370.

[35] Tocilizumab (Actemra) for giant cell arteritis. Med Lett Drugs Ther 2017;59:161-2.

[36] EMA/CHMP/431293/2017. RoActemra (tocilizumab), Committee for Medicinal Products for Human Use 2017. https://www.ema.europa.eu/en/documents/smop/chmppost-authorisation-summary-positive-opinion-roactemra-ii-66_en.pdf (accessed October 16, 2020).

[37] Adler S, Reichenbach S, Gloor A, Yerly D, Cullmann JL, Villiger PM. Risk of relapse after discontinuation of tocilizumab therapy in giant cell arteritis. Rheumatol Oxf Engl 2019;58:1639-43. https://doi.org/10.1093/rheumatology/kez091.

[38] Stone JH, Bao M, Han J, Aringer M, Blockmans D, Brouwer E, et al. Op0140 long-term outcome of tocilizumab for patients with giant cell arteritis: results from part 2 of the giacta trial. Ann Rheum Dis 2019;78:145. https://doi.org/10.1136/annrheumdis-2019eular.2099.

[39] Samson M, Devilliers H, Ly KH, Maurier F, Bienvenu B, Terrier B, et al. Tocilizumab as an add-on therapy to glucocorticoids during the first 3months of treatment of Giant cell arteritis: A prospective study. Eur J Intern Med 2018;57:96-104. https://doi.org/10.1016/j.ejim.2018.06.008.

[40] NCT04239196. Efficacy of Tocilizumab for the Treatment of Acute AION Related to GCA. Https://ClinicaltrialsGov/Show/NCT042391962020.

[41] Protocole National de Diagnostic et de Soins - Artérite à Cellules Géantes (Horton). 2017.

[42] Langford C, Cuthbertson D, Ytterberg S, Khalidi N, Monach P, Carette S, et al. A Randomized, Double-Blind Trial of Abatacept (CTLA-4Ig) for the Treatment of Giant Cell Arteritis. Arthritis Rheumatol Hoboken NJ 2017;69:837-845. https://doi.org/10.1002/art.40044.

[43] Walsh M, Merkel PA, Mahr A, Jayne D. Effects of duration of glucocorticoid therapy on relapse rate in antineutrophil cytoplasmic antibody-associated vasculitis: A metaanalysis. Arthritis Care Res 2010;62:1166-73. https://doi.org/10.1002/acr.20176.

[44] van der Geest KSM, Sandovici M, Brouwer E, Mackie SL. Diagnostic Accuracy of Symptoms, Physical Signs, and Laboratory Tests for Giant Cell Arteritis: A Systematic Review and Meta-analysis. JAMA Intern Med 2020;180:1295. https://doi.org/10.1001/jamainternmed.2020.3050.

[45] Rubenstein E, Maldini C, Gonzalez-Chiappe S, Chevret S, Mahr A. Sensitivity of temporal artery biopsy in the diagnosis of giant cell arteritis: a systematic literature review and meta-analysis. Rheumatol Oxf Engl 2020;59:1011-20. https://doi.org/10.1093/rheumatology/kez385.

[46] Duftner C, Dejaco C, Sepriano A, Falzon L, Schmidt WA, Ramiro S. Imaging in diagnosis, outcome prediction and monitoring of large vessel vasculitis: a systematic 
literature review and meta-analysis informing the EULAR recommendations. RMD Open 2018;4:e000612. https://doi.org/10.1136/rmdopen-2017-000612.

[47] Buttgereit F, Dejaco C, Matteson EL, Dasgupta B. Polymyalgia Rheumatica and Giant Cell Arteritis: A Systematic Review. JAMA 2016;315:2442-58. https://doi.org/10.1001/jama.2016.5444.

[48] Rinagel M, Chatelus E, Jousse-Joulin S, Sibilia J, Gottenberg J-E, Chasset F, et al. Diagnostic performance of temporal artery ultrasound for the diagnosis of giant cell arteritis: a systematic review and meta-analysis of the literature. Autoimmun Rev 2019;18:56-61. https://doi.org/10.1016/j.autrev.2018.07.012.

[49] Blockmans D, Luqmani R, Spaggiari L, Salvarani C. Magnetic resonance angiography versus $18 \mathrm{~F}$-fluorodeoxyglucose positron emission tomography in large vessel vasculitis. Autoimmun Rev 2019;18:102405. https://doi.org/10.1016/j.autrev.2019.102405.

[50] Sreih AG, Alibaz-Oner F, Kermani TA, Aydin SZ, Cronholm PF, Davis T, et al. Development of a Core Set of Outcome Measures for Large-vessel Vasculitis: Report from OMERACT 2016. J Rheumatol 2017;44:1933-7. https://doi.org/10.3899/jrheum.161467. 


\section{FIGURES TITLES AND LEGENDS}

\section{Figure 1: Flow diagram of study selection process}

Figure 2: Meta-analysis of the effect of adjunctive therapies on relapse rate at week 52

Rapid glucocorticoids (GC) tapering regimen:

- Tocilizumab subcutaneous (SC) rapid vs rapid: 6 months in experimental and control groups

- Sirukumab SC rapid vs rapid: 3 months in experimental group vs 6 months in control group

Rapid vs slow GC tapering regimen:

- Tocilizumab SC rapid vs slow: 6 months in experimental group vs 12 months in control group

- Sirukumab SC rapid vs slow: 6 months in experimental group vs 12 months in control group

Relapses between week 0 and week 2 are not included in sirukumab data (not available).

Figure 3: Meta-analysis of the effect of adjunctive therapies on GC cumulative dose at medium and long term

Data on GC dose were available at week 52 for tocilizumab, Stone et al. (14); tocilizumab, Villiger et al. (13); methotrexate, Hoffman et al. (16); etarnecept Martinez-Taboada et al. (12). They were available at week 96 for hydroxychloroquine, non-published (27); methotrexate, Jover et al. (31) and methotrexate, Spiera et al. (30).

Figure 4: Medium- and long-term relapse rate by GC tapering regimen, focus on tocilizumab (top), and other treatments (bottom). 